Article

\title{
Barriers to Managing Environmental Sustainability in Public Assembly Venues
}

\author{
Walker J. Ross ${ }^{1}$ and Haylee Uecker Mercado ${ }^{2, *}$ \\ 1 Barney Barnett School of Business and Free Enterprise, Florida Southern College, Lakeland, FL 33801, USA; \\ wross@flsouthern.edu \\ 2 Department of Sport and Entertainment Management, College of Hospitality, Retail and Sport Management, \\ University of South Carolina, Columbia, SC 29208, USA \\ * Correspondence: mercadoh@mailbox.sc.edu
}

Received: 25 November 2020; Accepted: 12 December 2020; Published: 15 December 2020

\begin{abstract}
Many sport and entertainment venues are still not major adopters of environmental social responsibility (ESR) despite evidence to suggest their benefit. This qualitative study investigated the major barriers that still prevent ESR adoption in public assembly venues (PAVs) used by sport and entertainment organizations. Using resource-based view (RBV) as a framework for analysis, PAV managers of stadiums, arenas, and performing arts centers were interviewed to collect data. Findings suggest a lack of resources to devote to ESR which displays an overall lack of priority given to ESR adoption and knowledge of ESR by PAV managers. If ESR was considered to offer competitive advantage, it would be given more priority, PAV managers would emphasize more training, and it would therefore receive more resource attention.
\end{abstract}

Keywords: sport ecology; environment; sustainability; barriers; management; venues

\section{Introduction}

Some organizations, in an attempt to expand their corporate social responsibility (CSR) initiatives, have looked to decreasing the harmful environmental impact of their activities by engaging in environmental social responsibility (ESR) [1]. While ESR may be a burden on an organization to cover, it also provides benefits to organizations including cost savings, competitive advantage, and beating regulatory efforts $[1,2]$. A case exists for organizations to take on ESR in order to improve their environmental performance, operation, and their bottom line [3,4]. Despite these benefits, the industry that supports the spaces where sport and entertainment take place, public assembly venues (PAVs), have not been as quick to adopt ESR despite the high priority placed by managers on the topic [5]. This shows that there remain PAV managers who are either not convinced that ESR adoption is beneficial to them or that they have some barriers preventing them from adopting ESR. If the PAV industry is to increase ESR adoption, then knowledge is needed about the barriers that prevent these managers from going green. What is more, while such barriers have been identified in other industries [6,7], there is no reason to believe that the barriers faced in these other industries are transferable to the PAV industry given the irregular pattern of usage of a PAV and its status as the capital necessary for the production of an event. Additionally, thus far a paucity of attention has been given by previous research to why the sport industry, in particular, has not been as quick to adopt ESR, and there have been calls for more research to be conducted on the topic [8].

Therefore, the purpose of this study is to explore the barriers to ESR adoption for PAV managers and to examine how those barriers are slowing ESR adoption in those PAVs. Using resource-based view of the firm as a conceptual framework, a qualitative study employing interviews was used to 
address the purpose of this study. As a result, this is the first study to focus directly on barriers to ESR adoption in PAVs as well as barriers to ESR in the sport management discipline in general.

\section{Literature Review}

\subsection{Resource-Based View}

The theoretical perspective of resource-based view (RBV) of the firm was chosen since it provides an explanation for managerial actions. RBV is grounded in the idea that sustainable competitive advantage of a particular firm within its respective industry is determined by effective use of the specific set of scarce and valuable resources that particular firm possesses that may not be replicated or substituted by competitors [9]. More simply, RBV posits that firm success is determined by how it utilizes its unique resources. Inter-firm differences in performance are a result of this difference in access to specific resources or a difference in prioritization of the use of those resources [10]. RBV is different than structuralist approach, which explains a firm's performance as largely determined by the structure of the industry within which the firm exists and operates [11]. For the purpose of the present research, the firm (or organization) in question is the PAV industry-particularly those focused on sport and entertainment live events.

There are multiple suggestions for the types of resources that may constitute a firm's whole resource profile. Hofer and Schendel posited that there are five major categories of resources that firms may employ to gain sustainable advantage: Financial, physical, human, technological, and organizational [12]. Barney simplified these categories of resources to simply physical capital, organizational capital, and human capital [10]. More recently, Løwendahl expanded upon these categories again to: Financial assets, tangible resources (e.g., production equipment and buildings), human resources (i.e., labor), and intangible resources (e.g., competency, reputation, and brand equity) [13]. ESR, when viewed as a resource, could arguably fit all of these various categories of resources. Wright suggested that tangible, non-tacit resources quickly diffuse through an industry, which means that advantages gained from those resources are not often held long-term [14]. Further, resources that are more tacit and intangible tend to remain as sources of advantage for longer periods of time [14]. With regard to PAVs, Mercado and Walker determined that ESR is seen as a valuable resource from the perspective of PAV managers, but that it is also not a resource that can be utilized by itself to provide any advantage [15]. As well, it does not substitute for other valuable resources. Where ESR is valuable is as a compliment for other resources like revenues generated from ticket sales or venue bookings [15]. If ESR adoption is considered to be tacit and intangible, this may help to explain a potential barrier to adoption of ESR throughout the PAV industry. Although the advantages of ESR are modest, one would expect to see greater proliferation of ESR practices in PAVs. So, barriers may still exist that are yet unexplained simply by RBV literature.

\subsection{ESR in PAVs and Sport}

The use of ESR in PAVs and in sport is a topic that has received growing attention recently with particular focus on measuring and understanding the environmental impact of sport activities [16]. However, some emphasis has been placed on PAV management since the PAV has one of the larger environmental footprints in the live events industry. Much effort has been expended in understanding the motivations for PAVs new and old to be environmentally sustainable. These motivations include pressure from stakeholders, financial benefits, competitive advantages, organizational culture, and ethical motives $[17,18]$. It is also important to acknowledge that some PAVs (e.g., larger markets and publicly owned PAVs) are more likely to engage with ESR than their peers [5]. Given this information, it would be fair to expect that PAV managers would be motivated to incorporate ESR into their operations. Additionally, MacIntosh, Apostolis, and Walker argue that sport industry consumers are moderately aware of environmental responsibility and the argument is made that due to these expectations of sport consumers, managers ought to be engaged with ESR if they are not already [19]. 
However, despite these stated benefits and rationale for ESR adoption, there remain a large share of PAVs in this industry which have yet to engage with ESR. While Walker, Salaga, and Mercado report that 86 percent of managers operate some sort of environmental program in their venue (e.g., recycling programs, renewable energy sourcing, and the use of biodegradable disposable materials), only 42 percent of those managers had a green task force and only 32 percent had undertaken green retrofitting [5]. These figures do not provide any insight into the level of impact that ESR has had on the organization or depth of their participation with ESR. What this indicates is that there remain a large number of PAV managers that have not adopted ESR. As well, not all PAV managers that have adopted ESR are doing what might be socially optimal. For these PAV managers that have not adopted ESR or who refuse to increase their engagement with ESR, it is imperative to build an understanding of what prevents them from increasing their ESR efforts.

\subsection{Known Barriers to ESR Adoption in Sport and Entertainment}

There is limited information available that suggests barriers to ESR adoption in sport and entertainment PAVs. Kellison and Hong have called for further research in the subject to be conducted [17]. Common sport barriers in the available research have included lack of desire from leadership to act, costs, resource availability, avoiding the appearance of greenwashing, and a lack of knowledge and training on the subject [17,19-25]. However, there are limitations in all of these studies that prevent them from accurately addressing the research question posed by the present study. Most notably, none of the studies have attempted to address the question of barriers and merely offer anecdotal evidence on the matter that are unrelated to the primary purpose of their studies. More specifically, some studies focused only on the design phase of environmentally sustainable venues, which leaves out non-environmentally sustainable venues and already operational venues that ought to be included in this research $[18,22]$. Other studies have focused on too narrow of contexts like one geographic region or venues only found at small venues at universities with budgetary restraints $[20,25]$. The limitations of all of the previous studies are significant enough that they do not accurately describe issues regarding ESR barriers in sport and entertainment PAVs and how these barriers may affect ESR adoption.

A qualitative approach to exploring PAV manager perceptions of barriers to ESR adoption is necessary in order to evaluate the manager's recognition of these suggested barriers as well as to explore how these barriers impede those PAV managers who wish to expand their ESR programs. Moreover, these studies do not utilize a resource-based view of the firm, which is a more appropriate framework from which to analyze such barriers and was employed by the present study.

\section{Materials and Methods}

\subsection{Data Collection}

This study utilized a qualitative approach centered around the use of interviews and focused on sport and entertainment PAV managers regardless of their current level of engagement with ESR. Qualitative methods were preferred since they offer a deeper understanding of how PAV managers experience and perceive barriers to ESR adoption that would be not be uncovered via a quantitative approach. Interviews were chosen for use since they allow a researcher to explore the experiences, motives, and opinions of others from their viewpoint [26]. This study employed interview techniques similar to that of previous studies of ESR in PAVs [17]. Previous literature and data were considered in order to create a semi-structured interview guide of sixteen questions that offered the best opportunity for collecting quality data from participants (see Appendix A for interview guide). Questions were designed to create an in-depth interview that allowed participants to describe their PAV and current experience with ESR and offer their own barriers. Then, participants were asked to present solutions they believed would be helpful in overcoming barriers they had mentioned. This semi-structured interview allowed the researchers to ask questions that accurately evaluated the presence of barriers to 
ESR while allowing the participant to freely answer and provide information that they feel is relevant to the study [26]. If, in a response, the participant discussed a new potential barrier or presented a confusing answer, they were asked further questions to clarify their statement. Since the interview guide was designed to require participants to directly answer questions on their barriers to ESR adoption, it is believed that this study will appropriately address its primary purpose and thus possess content validity [27].

A total of thirty-one PAV managers were initially contacted via email to recruit them to the study, and sixteen of those contacted were responsive and available for conducting interviews (see Table 1 for sample information). Another four of the PAVs contacted claimed they could not assist with the present study since they lacked knowledge on sustainability. All sixteen interview participants were from the United States and were from a variety of geographic regions within in the United States. These interviews lasted between 30 to $45 \mathrm{~min}$. Interviews were recorded, transcribed, and sent back to the participant to ensure the accuracy of the transcriptions [26]. Participants were purposely sampled via the Green Sports Alliance (GSA) and the International Association of Venue Managers (IAVM) since it allowed the research team to select a smaller number of rich cases for interview that still yield sufficient information for data analysis [28]. The sample included managers of PAV that were identified as members of the GSA, an organization that promotes ESR in sport venues [29], as well as venues who were not members of the GSA. This distinction of GSA members versus non-members was considered essential to identifying PAVs as non-adopters of ESR. As stated in the literature review, including non-adopters of ESR is necessary to understand why PAVs are not adopting ESR. Once non-members were selected, further participants were sampled from the IAVM, a professional association of PAV managers which includes managers for auditoriums, arenas, convention centers, exhibit halls, performing arts centers, stadiums, university complexes, and amphitheaters [30] based on the work of Mercado and Walker [18]. The total sample included managers of indoor multipurpose arenas, outdoor stadiums, and a performing arts center, all of which host a mixture of sport and entertainment live events. It also included managers of publicly-owned PAVs, privately-owned PAVs, and university-affiliated PAVs. As professionals working in the PAV industry, these managers were the most credible sources for acquiring data on venue operations and ESR within those PAVs [26].

\subsection{Data Analysis}

Content analysis was used as the primary method of analyzing collected interview data. All transcriptions were coded in an initial open coding cycle using ATLAS.ti software for all references to barriers to ESR adoption. This initial step identified relevant pieces of data from the transcriptions through an open coding cycle [31]. Codes for subsequent cycles were generated through a combination of inductive and deductive processes with Løwendahl's resources categories assisting in the development the deductive codes [12]. Via further coding cycles, this coded data was grouped into categories of related information that are more specific based on previous literature and RBV (e.g., lack of resources, lack of commitment, and logistics issues) [31]. During this second coding cycle, networks were created in order to identify patterns in the data that describe higher order themes of barriers [31]. It is important to note that that the research team consists of proponents of ESR and that no member of the research team is a current GSA member, but that this positionality is not believed to have impacted the data collection or analysis.

Upon completion of the sixteenth interview, interview responses were presenting no new or novel information, which suggested that a point of saturation had been reached. The decision was made to stop collection of further interviews. It is believed that the present study is reliable due to the strength of this methodology and that a similar study would yield the similar results [26]. 
Table 1. Summary of interview participants.

\begin{tabular}{|c|c|c|c|c|c|}
\hline Pseudonym & Venue Type & Primary Use(s) & Position & GSA Membership & Interview Type \\
\hline John & Stadium & Racing & Former President & Yes & Telephone \\
\hline Samuel & $\begin{array}{l}\text { Athletic } \\
\text { Complex }\end{array}$ & $\begin{array}{l}\text { Soccer, } \\
\text { basketball, } \\
\text { baseball }\end{array}$ & $\begin{array}{l}\text { Associate Athletic } \\
\text { Director for } \\
\text { Operations }\end{array}$ & Yes & Telephone \\
\hline Paul & Stadium & Baseball & Director of Facilities & No & Telephone \\
\hline Thomas & Arena & $\begin{array}{l}\text { Basketball, } \\
\text { Hockey }\end{array}$ & $\begin{array}{l}\text { Director of } \\
\text { Operations }\end{array}$ & No & Telephone \\
\hline Jessica & Arena & Basketball & $\begin{array}{l}\text { Operations } \\
\text { Coordinator }\end{array}$ & Yes & Telephone \\
\hline Adam & Arena & Basketball & General Manager & No & In-person \\
\hline Cameron & $\begin{array}{l}\text { Performing } \\
\text { Arts Center }\end{array}$ & Ballet, Theater & Assistant Director & No & Telephone \\
\hline Timothy & Arena & Basketball & $\begin{array}{l}\text { Assistant General } \\
\text { Manager }\end{array}$ & No & Telephone \\
\hline Scott & Stadium & Football & $\begin{array}{l}\text { Assistant Athletic } \\
\text { Director for } \\
\text { Facilities/Services }\end{array}$ & No & Telephone \\
\hline Michael & Arena & Multipurpose & $\begin{array}{l}\text { Director of } \\
\text { Operations }\end{array}$ & No & Telephone \\
\hline Franklin & Stadium & Football & Former President & No & In-person \\
\hline Peter & Stadium & Football & $\begin{array}{l}\text { Recycling } \\
\text { Coordinator }\end{array}$ & No & In-person \\
\hline Mary & $\begin{array}{l}\text { Athletic } \\
\text { Complex }\end{array}$ & $\begin{array}{l}\text { Football, } \\
\text { basketball, } \\
\text { baseball }\end{array}$ & $\begin{array}{l}\text { Assistant Director of } \\
\text { Facilities and Event } \\
\text { Management }\end{array}$ & No & Telephone \\
\hline Bill and Sarah & Stadium & Soccer & $\begin{array}{l}\text { President/COO and } \\
\text { Office Manager }\end{array}$ & No & Telephone \\
\hline Lewis & Stadium & Baseball & $\begin{array}{l}\text { Director of Stadium } \\
\text { Operations }\end{array}$ & No & Telephone \\
\hline Ben & Stadium & Baseball & $\begin{array}{l}\text { Director of } \\
\text { Operations }\end{array}$ & No & Telephone \\
\hline
\end{tabular}

\section{Results}

The results are grouped into the four major resource themes as described by Løwendahl [13]. As such, the findings section is broken into four themes: Financial assets, tangible resources, human resources, and intangible resources.

\subsection{Financial Assets}

Financial assets are considered to be one of the fundamental categories of resources according to RBV [12,13]. Costs and lacking financial resources were widely mentioned in the literature as a barrier to ESR adoption across industries $[7,20,25]$. This theme includes any discussion related to financial issues of the PAV, which included both the high costs to initial implementation of ESR as well as a lack of the necessary funds to cover implementation of any additional ESR practices. All references to funding, costs, and money were considered to share the common theme of being financial assets necessary for PAV managers to implement ESR. The current research found that lacking these financial assets is a major barrier as they were the most frequently cited problem regarding ESR adoption in PAVs. All sixteen PAV managers interviewed mentioned an overall lack of resources, while eight specifically mentioned a lack of financial assets for ESR. PAV managers understand the long-run return on investment that exists for certain ESR practices like energy saving and water reducing measures. The resource issue is not for a lack of knowledge on the budgetary benefits of ESR nor a lack of 
knowledge on the practices themselves. However, the data suggests a recurring theme of insufficient financial assets for making the initial investment in ESR adoption. Michael, the director of operations at a multipurpose arena suggested that in regard to financial assets: "There is never enough money. It doesn't matter what stadium you are at or what arena you are at, there is never enough money to do everything that you want to do" (Michael, 16 August 2017). This sentiment was echoed by the fifteen other PAV managers that directly mentioned a lack of financial assets as one of their major barriers. There are always limitations to the amount of funding or the access one has to funding.

Due to the limitations placed on financial assets as a resource, PAV managers are forced to make decisions with regard to the scarcity of that resource. Financial flexibility is an important resource for PAV managers for addressing all projects and operational issues, not just ESR, in their PAVs. As an example of how finances tend to be spread thin as a resource for PAV managers, Cameron, an assistant director at a publicly owned performing arts auditorium, provided the following story regarding competing interests and project prioritization:

"We have a huge list of projects that constantly need to happen [ . . ] Y You sort of have to rank them between what we would like to do and what we need to do. Even those ones that you feel that you need to do have to get rated in some way as to which ones you do first [ ... ] The budget tends not to change a lot, but things keep breaking. So, you are constantly battling what you can spend your limited amount of discretionary spending on." (Cameron, 6 April 2017)

Cameron was suggesting that while there is money available for discretionary projects, managers often are forced to use those financial assets on projects that are either more immediate in their nature or generate revenues rather than amenities to their PAV. Infrastructure requires repairs, maintenance, and replacement. Thus, just keeping the PAV functional often requires an allocation of the available financial assets for operations. ESR is often competing for those same financial assets, but is not deemed as operationally necessary in comparison.

A solution to the lack of financial assets would be to acquire more, yet when it comes to them as a resource, it is often not possible to simply acquire more money or a larger budget allocation. For some PAVs, when simply staying open and operating is an issue, decisions are made in favor of those practices that are revenue generating in nature:

"When you are making choices, things have to compete for those resources: Money. There are going to be decisions that get made and the things that are going to make it at the end of the day are things that create revenue or save operational expenses." (John, 22 February 2017)

Thus, if a practice can be adopted or a project undertaken, the managers tend to favor those that are able to either generate revenue or save money on existing expenses. These types of projects help to keep PAVs open, operational, and possess less risk for the manager. This also continues to highlight the fact that financial assets for managers are limited. Decisions must be made on how to allocate it as a scare resource and ESR may not be the most immediately beneficial project for a PAV manager. However, the upfront cost for implementing an ESR is not the only resource issue that managers identified.

\subsection{Tangible Resources}

Outside of PAV management, managing the balance of customer expectations of service with the proper infrastructure to support ESR adoption has been explored as a potential barrier [6]. Mercado and Walker noted that lack of infrastructure was a deterrent to PAV managers that they surveyed as well [18]. This is an issue as it requires changing the physical resources available in the venue (e.g., electrical capacity or adding space) to support the adoption of ESR practices. These issues are related to the use of what Løwendahl deemed to be tangible resources [13]. Thus, references to changing infrastructure, utilities, spacing issues, and dealing with the age of the building were 
considered to share the common theme of a lack of infrastructural support, which prevented ESR adoption. Twelve PAV managers noted that tangible resource concerns were a hindrance to their adoption of ESR.

A lack of proper utility support was a common issue for preventing the adoption of ESR in PAVs. Managers may be interested in adopting a certain ESR practice only to find that their building is not able to support that practice without additional upgrades to the infrastructure. As an example, this university-owned multipurpose arena manager, Thomas, noted the following in regard to adopting ESR in their venue:

"The fact is that it would just be the logistics of the building: that it was built so long ago with no regard for that potential. So, we don't have the logistics really in place at the moment to make it work on the property [ ... ] It's just the building is older and trying to figure out how to design around the restraints we have at the moment." (Thomas, 23 March 2017)

Thomas notes through the term "logistics" that their PAV lacks the utility systems necessary to take on certain ESR practices due to the age of the building. When their PAV was constructed, there were no considerations made with respect to for some of the ESR practices and technology that would be available in the future. So, for Thomas, the building might require many utility upgrades to their tangible resources before more modern ESR amenities like can be successfully installed and implemented.

In a more specific case regarding utilities, Adam, the manager of a university-owned multipurpose arena, suggested that: "when I'm talking about cost, I'm not talking about the cost of the actual device, but are you going to have to bring new transformers in" (Adam, 29 March 2017). This overlaps with the previous resource theme above of needing financial assets. Yet, Adam went on to discuss the potential for installing more hand dryers in the restrooms of the PAV in place of paper towel dispensers, but that the PAV may not be equipped with the electrical capacity to handle the addition of a large number of hand dryer units. Thus, even though there would be sufficient funding for the dryer units, and time available to install them, the PAV lacks the electrical capacity (i.e., utilities) to install the units. In addition to utilities issues, there is also a lack of space issue to consider as well.

Another issue regarding infrastructure is the lack of space within the PAV itself to put equipment necessary for some ESR practices. A lack of space may be difficult to overcome as it requires building onto the PAV itself or contracting with outside vendors. In regard to implementing a recycling program, Cameron asked in regard to recycle bins: "Where do we put those" (6 April 2017). One example of how the lack of space impacts PAV managers was explored by Jessica, who manages a multipurpose arena, when she suggested the following regarding spacing for adding extra equipment:

"Where we are going to put things? Battery recycling means adding another recycler because it's not something [a waste company] picks up. So, we've had to find another regular e-recycler to come on site to pick up battery recycling and those types of things. Making sure that we are producing enough that it justifies them coming out." (Jessica, 29 March 2017)

Jessica notes the infrastructural deficiency regarding space. Adding a battery recycling program to their PAV requires adding another recycler, but they do not have the space to put one anywhere. Further, since they lack space, if they wanted to implement the battery recycling program anyway, they would have to contract with an outside vendor to manage the recycling program for them since they are unable to do so themselves. Jessica goes on to question in battery recycling is worth this effort.

In all of these examples, the insufficiency of tangible resources was a concern for the managers and these insufficiencies manifest themselves through issues with the building and equipment like the age of the building, utility deficiencies, and the lack of available space. Some managers felt that in order to overcome these challenges, they would have to contract with outside vendors. Those outside vendors may not be worth their expense, which links these tangible resources with financial assets. With these two resources addressed, attention may be given to human resources. 


\subsection{Human Resources}

One issue cited in previous research suggested that human resources may be one of the barriers to the implementation of ESR. Human resource issues could take many forms, which included an overall lack of person power, a lack of commitment from senior-level management, and insufficient training on the subject $[7,20,25]$. As such, human resources were an emergent theme in the data and this theme included any references to such person power, staff commitment, and training and expertise. Of those PAV managers interviewed, there was a near unanimous consensus on issues of commitment as well as training and expertise. Thirteen of the PAV managers interviewed felt that they had complete buy-in from senior level management and employees. These PAV managers felt that ESR made both business sense and were ultimately an expectation of their customers, community, and other stakeholders. Scott, a manager for a university-owned football stadium, had said the following with regard to commitment to ESR: "Everybody's bought into it. Our whole department does it. We do it at all of our facilities. We do it at all of our administrative buildings. We do it at all of our stadiums" (Scott, 14 July 2017). Another PAV manager, Mary, who oversaw a variety of university-owned athletic PAVs provided a different, albeit common sentiment for those venues that are more neutral on commitment: "I would say we are neutral on that. I think to a certain extent: yes, but I also don't think we are going to work against it" (Mary, 20 March 2018). Considering no PAV manager indicated that they were working directly against ESR, the data suggest that these PAV managers believe commitment from senior-level management was not immediately a barrier to their potential adoption of ESR.

An even larger portion of the managers interviewed, fifteen of the sixteen interviewed, felt that there was adequate training and information on the ESR available to them. However, the four PAV managers who responded to requests for interviews that declined to interview, indicated that they chose to decline due to a lack of knowledge on ESR and their operations. Plus, one lone PAV manager, Cameron, simply replied with "no" when asked if he believed that there was sufficient training and information available on ESR. On the subject of the availability of training on ESR, Timothy, who manages a university-owned multipurpose arena said:

"I feel like this topic, especially these days, is starting to be a very big topic of discussion at most trainings and facility management organizations and things like that. You are always hearing about it and hearing about the new things." (Timothy, 30 June 2017)

This quote and the support of the other PAV managers suggests that ESR is a popular discussion point at conferences and in other training settings. Jessica suggested that PAVs are even willing to share this knowledge and expertise with one another to ensure the overall success of ESR in the industry: "We talked to so many other [league] buildings who were just so open and willing to share their information and story ... Their management staff over at [another team] was just overwhelmingly willing to share every bit of information about their program" (Jessica, 29 March 2017). This also provides support for the notion that these PAV managers believe training is not a barrier that is preventing them from adopting ESR. Yet, when asked a question regarding what further ESR practices each venue could adopt, many of the interviewed PAV managers struggled to identify a practice beyond solar panels and recycling. This would suggest that their knowledge on the subject is limited if so many are unable to identify other ESR practices that could be implemented.

However, human resources refers to person power and labor more so than it does commitment and training. Yet, none of the PAV managers expressed that they lacked the person power to adopt ESR. Those that did discuss person power and labor felt that their staffs were competent and large enough to handle all of the duties expected of them as expressed by Timothy:

“Our operations team here is very good... They bring a lot of these things to my attention that I might not even be aware of to make sure that we are staying on top of trying to stay ahead of the game with a lot of this stuff." (Timothy, 30 June 2017)

What this quote, as well as the other human resource related findings suggest is that the PAV managers interviewed largely do not consider human resources to be considered a potential barrier to 
the adoption of ESR. However, in consideration of those that did not respond to interview requests as well as Cameron's response, there may actually be some underlying human resources issues that PAV managers are not acknowledging, specifically a lack of commitment and training, which do serve as barriers.

\subsection{Intangible Resources}

Resources that fit under this category of intangibility include competency with ESR, brand equity, and reputation according to Løwendahl [13]. Previous research outside of PAVs suggests that logistical issues are also a potential barrier to ESR adoption, which would fit as an intangible resource [6,7]. Related to logistics, one resource dominated the conversation: Time. While all PAV managers indicated that there was commitment to ESR from all levels of employees and management, there are the issues of the timing of events at these PAVs as well as the time necessary for implementing ESR. Ten of the venue managers mentioned that they lacked enough time between events as a resource when it came to their operations and thus adopting ESR. It was noted that work time for events in these PAVs is often during the leisure time of the general population and that the hours are irregular. When it comes to finding the time necessary for adopting and implementing ESR Adam noted:

"A lot of it is the time that you have to go from one event to another. Even if it's not two events back-to-back, we're cleaning. If we have a concert that lasts until midnight, well people then are cleaning ... How much can you expect of your staff if you are asking them to stay until four in the morning to clean and then be back at eight the next morning to work their regular day shifts?" (Adam, 29 March 2017)

In this statement, the participant noted that it is not as easy to take proper care for ESR when workers are already constrained due to the timing of when they are required to work.

In an example of how a lack of time affects PAV managers, Scott noted that the lack of time prevented them from adopting further waste management practices: "Just the constraints of: it's a big endeavor. It's not small. It takes us four days to clean up the stadium. So, it's not like you just come in and sweep it up and Sunday afternoon you are done" (Scott, 14 July 2017). Scott went on to include that: "It's just time consuming. It's a big place... With it being as massive as it is, it just takes a few days" (Scott, 14 July 2017). This sentiment regarding the scale of the endeavor was echoed by a former executive for a football stadium, Franklin, who agreed that when considering parking lots as part of the PAV that the effort required increases (5 September 2017). Here, time is also an issue as it takes several days to simply clean the stadium, pick up trash, and recycle. By the time this is completed, the PAV already needs to start planning for the next football game, which leaves little time to implement other ESR practices that deal with waste. Similarly, Michael mentioned the same problem when it came to properly sorting and disposing of recyclables and trash:

"A lot of times it's on the family show side where they want to do three shows on a Saturday. You have an hour and a half between doors, so on those days there is not enough time or manpower to get everything sorted. It's kind of just 'get it up and get on with it.'" (Michael, 16 August 2017)

In both examples, time is of the essence for executing the basic functions necessary to turn over a PAV for a different event. There simply is not enough of it available to allow for certain ESR practices to be properly implemented. Thus, it is a priority to simply turn over a PAV from a completed event to a brand new one just to keep it functioning properly rather than to be environmentally sensitive. This suggests that it is important not just to have funding resources, but also to have the time to ensure that these practices can be implemented properly.

Furthering the lack of time as a resource problem is being able to properly plan ahead for any potential problems within the PAV. Samuel, a university athletic complex manager, described this problem as: "not knowing what's around the corner" (Samuel, 3 March 2017). It takes proper planning 
in the long and short terms to ensure that ESR is successful when implemented. This is difficult to accomplish when you are uncertain of the future and do not have the time to properly complete this planning process. Thus, this lack of time could also affect PAV managers since they may lack enough time between events to complete major upgrade projects and they may not be able to plan ahead for the unexpected projects that are more immediate in nature. So, the data suggests that time for these PAV managers, as an intangible resource, is lacking and may be preventing the adoption of ESR in venues. With the identification of all the themes of financial assets, tangible resources, human resources, and intangible resources, it is important to further discuss these findings within the context of RBV.

\section{Discussion}

The present research reaffirms findings in previous studies in the context of sport and entertainment venues with regard to barriers to ESR adoption and builds new knowledge on the subject. All of the resources identified by Løwendahl were present in the data [13]. Firstly, issues surrounding the lack of financial assets supports previous research in sport management on ESR barriers as well as research in other industries $[7,18,20,25]$. Financial resources are a major consideration for PAV managers, and this shows that managers view ESR as a non-priority compared to other financial considerations [32]. This is especially true during difficult economic times like a recession or pandemic when basic financial interests may drown out the interests of ESR. Normally, ESR projects in PAVs may only move forward if there is a demonstrable return-on-investment since budgets are tight. Many of these ESR projects may take place on an as-needed basis rather than all at once and the budgets do not account for the whole cost of the project rather than just the cost of the necessary equipment.

Outside of the financial constraints, the lack of tangible resources was common in the previous literature $[7,18]$. Human resources were not ultimately seen as an issue by these PAV managers, which differentiates PAVs from other areas where human resources did serve as a barrier [7]. Lastly, intangible resources were present in the findings and mainly expressed as time. Yet, the lack of time was a theme that was not thoroughly explored in previous research. Thus, the present research contributed to the literature through its exploration of time as a theme. Specifically, time was an issue for PAV managers as they lacked enough time between events to ensure ESR is followed or to implement new ESR practices. When PAV managers must move from one event to the next in short order, there is often not enough time to install new infrastructure or implement a new program in the venue. The priority in those moments is getting the PAV ready for the next event. The lack of these resources (i.e., financial assets, tangible resources, and intangible resources) puts PAV managers in a position where they must make decisions on what to prioritize to give their venue the best chance to succeed, which may lead to unsuccessful adoption of ESR. This validates the basic premise of RBV since the lack of proper utilization of these resources may explain the differences in successful adoption of ESR in venues $[9,10]$. Therefore, those PAVs that are lacking these resources or are unable to prioritize those resources effectively are facing barriers for successful adoption of ESR that their peers are not facing.

In this research, the author extends the use of RBV into the literature on PAV management. While RBV has previously been used in an event management context it had not previously been utilized in examining problems facing the PAVs necessary for hosting an event [15]. In the sport and entertainment PAV industry, adoption of ESR varied across the PAVs interviewed, which suggests that those PAVs who were more successful adopters of ESR may have access to certain resources that gives them the distinct advantage they hold in the industry regarding this topic. This supports the basic premise of RBV which suggests that differences in firm success in an industry may be the result of differences in the unique sets of resources they possess $[9,10]$. Yet, unlike in other industries and the premise of RBV, where competition drives the desire to keep resources knowledge secret in order to maintain that competitive advantage, in the PAV industry the sharing of information was found to be common at conferences and with peer-to-peer interaction among PAVs. As such, access to resource knowledge and methods of prioritization should level the playing field for PAVs and therefore should 
not be preventing the adoption of ESR within the industry. However, this does not mean that resource access is equal across the industry, which is evidenced by the various levels of ESR adoption found across PAVs [5].

The view of time as a resource is interesting for RBV. It is also neither rare nor unique per the requirements of Hofer and Schendel [12]. Although it may be considered an intangible resource, the inclusion of time as a resource may build upon RBV literature by suggesting that it is a resource that may give a firm a potential advantage of overs. These PAV managers cited a lack of time between events as one of the reasons that they were not able to adopt ESR, yet it is possible that time is a barrier that prevents venues from gaining access to the other resources they lack like financial resources or infrastructural support. Having more time between events would be an advantage to a PAV manager as it allows them the opportunity to budget for financial resources or make infrastructural upgrades. Additionally, time to address how ESR may be utilized in response to other more pressing matters like economic downturns, pandemics, and social unrest. Time is also important to consider as the PAV itself is not simply the firm, service, or capital to production of a product. Unlike the Indian automobile industry, but similarly to the luxury hotel industry, the PAV is the product itself. The PAV is not strictly a service or producing goods for consumers. This makes PAVs somewhat unique in the context of business and makes this research on barriers to ESR adoption all the more unique. So, time is potentially a unique resource for an industry that does not strictly produce a good or a service.

Another interesting finding concerns the belief that the majority of PAV managers interviewed held regarding the availability of training and expertise on ESR. While only five total PAV managers admitted to either not knowing enough on the subject or there not being enough information available to them, the majority of those interviewed felt comfortable with the knowledge they had. However, when pressed, they were not able to display a thorough understanding of the subject as it related to their venues. As such, it is a dangerous combination if these PAV managers truly do not possess the training on the subject of ESR while believing that they do. This would make training as it currently stands a barrier to the adoption of ESR and supports previous suggestions that knowledge may be a barrier to ESR adoption [21,23]. This might imply that ESR training is a non-tacit resource [14]. As such, that knowledge might not disseminate as quickly as these PAV managers believed it does. The difference in their experience with and knowledge of ESR shows that training may be a rare or unique resource since it has not spread as quickly as it otherwise could [12].

An important point regarding RBV is the notion that the financial assets, tangible resources, and intangible resources are not necessarily easily replicable resources for other PAVs. Wright suggested that resources that are tangible and tacit (e.g., easily understood) are more likely to spread throughout and industry and thus reduce the advantages that a specific firm may have [14]. Some resources, like infrastructure in the PAV, are tangible and spread throughout the PAV industry easily, which gives all venues access to those resources. The alternative intangible resources-specifically financial assets and time-provide firms with an advantage and thus does not proliferate across and industry as quickly [14]. Financial assets and time are intangible resources that can easily be accessed or replicated by other PAVs. They are unique for each PAV. Additionally, it is important to consider a knowledge of how to utilize those scarce resources for ESR in PAVs. As shown in the human resources findings, certain knowledge is shared across the industry and that specific knowledge may be believed to be tacit. However, there remain several key differences between PAVs that is likely a barrier: Knowledge of adoption of ESR may be unique for each specific PAV. What will work for a baseball stadium is not necessarily transferable to what would work in a basketball arena or a race track. If this knowledge is truly not tacit, then RBV would help to explain the presence of these barriers within the PAVs industry. Thus, advantages regarding the adoption of ESR remain for certain PAVs due to their access to intangible resources or non-tacit information, which would help to explain the differences in ESR adoption across the industry. Thus, the present research supports Wright's work with regard to RBV [14]. 
Perhaps the most significant development of this research is the agreement with Mercado and Walker's finding that ESR, while generally viewed as a valuable resource, is not significant enough on its own to create a competitive advantage [15]. The premise of RBV suggests that firms acquire a competitive advantage through the use of resources that are available to them that are not available to their competitors [9]. The findings from the present study suggest a lack of resources available to these PAV managers to implement ESR. Those resources that are available to these PAVs (i.e., the financial assets, tangible resources, human resources, and intangible resources like time) are being utilized to keep the doors open, the events coming, and the lights on. In the findings, resources were prioritized for turning over events quickly to get new ones in, only spending on essential operational expenses, or changing old infrastructure to bring it up to the current standards. If there are resources available, then they are being prioritized to other projects that are deemed to be immediately more beneficial and which may provide a competitive advantage: Revenue generation or saving on operational expenses. Thus, the idea of being an environmentally sustainable PAV is not seen as creating a competitive advantage when some PAVs are simply competing to stay open and operational. Therefore, what the overall theme of lacking resources suggests is that ESR is simply not the priority for these PAV managers.

There are other issues that require their scarce resources and attention that are prioritized over ESR. For example, PAV managers may utilize available time for those essential projects rather than to educate themselves on ESR. RBV suggests that those essential projects are the ones needed to remain competitive or even acquire a competitive advantage over others in the industry [9]. So, in conjunction with the findings from Mercado and Walker, these PAV managers do not prioritize putting resources towards ESR or training themselves on ESR because they do not perceive ESR as valuable enough to gain a competitive advantage within the industry [15]. Otherwise, if ESR were valuable enough on its own as a resource to gain competitive advantage, RBV suggests that more priority would be placed on putting other resources towards ESR. As such, the most important implication of these findings is the understanding that ESR remain a non-priority for many sport and entertainment PAV managers.

\section{Conclusions}

The primary purpose of this paper was to directly explore barriers to ESR adoption in the sport and entertainment PAV industry in both buildings which had adopted ESR as well as those that had not yet adopted ESR. Findings from the present research found that within the sport and entertainment PAV industry, the major barriers to ESR adoption remains a lack of priority placed on it as a resource and a lack of training (or knowledge) on the subject since ESR is still not considered to be a creator of sustainable competitive advantage over other PAVs. Four resource deficiencies emerged in the interviews which led to this conclusion: Lack of financial assets, lack of tangible resources (e.g., age of the building, lack of utility support, or a lack of space), lack of human resources (e.g., commitment and training), and the lack of intangible resources (e.g., time). Ultimately, due to these barriers to ESR adoption and resource deficiencies, sport and entertainment PAVs are missing an opportunity to expand programs which would benefit their business as well as the community.

The findings of the study are preliminary and ought to be explored in more detail in future research. The most significant limitation of this study is the lack of generalizability of qualitative research. However, this research provides the foundation for a more broad and generalizable quantitative study of barriers to ESR adoption across the whole sport and entertainment PAV industry as well as in sport management in general. Future research should consider gathering the perspectives of multiple employees within a PAV or the influence of stakeholders in the decision-making process for ESR adoption. Some PAV stakeholders may push for or against ESR adoption more than others. Alternatively, perhaps some operational practices are institutionalized and should be examined through the lens of institutional theory. Additional research should also focus on addressing potential solutions to the barrier themes presented in this study. There may be methods that would increase the sharing of information between PAVs so that they may properly plan for ESR adoption in order to increase CSR 
efforts as well. Through these solutions, ESR adoption, and more broadly CSR efforts, can be advanced forward in the sport and entertainment PAV industry.

Author Contributions: Conceptualization, W.J.R. and H.U.M.; methodology, W.J.R.; software, W.J.R.; validation, W.J.R.; formal analysis, W.J.R. and H.U.M.; investigation, W.J.R. and H.U.M.; resources, H.U.M.; data curation, W.J.R.; writing—original draft preparation, W.J.R. and H.U.M.; writing—review and editing, W.J.R. and H.U.M.; supervision, H.U.M. All authors have read and agreed to the published version of the manuscript.

Funding: This research received no external funding.

Conflicts of Interest: The authors declare no conflict of interest.

\section{Appendix A. Interview Guide}

Part I: Introduction

1. Tell me about your venue.

2. What types of events are held in your venue?

Part II: Identifying ESR practices

1. Does your venue utilize any environmentally sustainable practices?

a. If yes, what practices have been implemented?

2. Does your venue have a green task force?

a. If yes, who is a part of that task force? What are its responsibilities?

3. Are you certified by the Green Sport Alliance, LEED, or any other similar organizations?

Part III: Identifying Barriers

1. All potential restraints aside, what other environmentally sustainable practices could be implemented in your venue?

2. What makes prevents those practices from being implemented?

a. Why do those restraints exist?

3. Tell me about senior management and staff commitment to environmental sustainability in your organization?

4. Tell me about your venue's stakeholders with regard to environmental sustainability?

a. Owners? Tenants? Employees? Food suppliers? Trash removal?

5. Is there adequate training and education on the subject available to you?

6. How do costs impact your stance on environmentally sustainable practices within your venue?

a. Is return on investment a factor in your discussion of costs?

7. Do you feel that your venue lacks the proper infrastructural support for environmental sustainability?

a. Do you have the space you need to install extra equipment or infrastructure necessary for certain ESR practices?

8. How much time and effort does it take to implement environmentally sustainable practices within your venue?

a. Does time between events impact your ability to successfully implement ESR?

b. Do you have enough personpower to successfully implement ESR?

9. Do your customers demand environmental sustainability? Does that matter to your organization?

a. Does their engagement with ESR impact your ability to successfully implement them?

Part IV: Overcoming Barriers 
1. Of the barriers you have identified in your organization, what are potential methods for overcoming those barriers?

a. How do you increase funding or allocate funding more efficiently?

b. How do you address increasing commitment from leadership?

c. How do you address research, planning, and logistical issues?

Part V: Conclusion:

1. Is there any other information you would like to add?

\section{References}

1. Babiak, K.; Trendafilova, S. CSR and environmental responsibility: Motives and pressures to adopt green management practices. Corp. Soc. Responsib. Environ. Manag. 2011, 18, 11-24. [CrossRef]

2. Graci, S.; Dodds, R. Why go green? The business case for environmental commitment in the Canadian hotel industry. Anatolia 2008, 19, 251-270. [CrossRef]

3. Bansal, P.; Roth, K. Why companies go green: A model of ecological responsiveness. Acad. Manag. J. 2000, 43, 717-736.

4. Carroll, A.B.; Shabana, K.M. The business case for corporate social responsibility: A review of concepts, research and practice. Int. J. Manag. Rev. 2010, 12, 85-105. [CrossRef]

5. Walker, M.; Salaga, S.; Mercado, H.U. Determinants of managerial engagement in environmental responsibility in the public assembly facility sector. Manag. Decis. 2016, 54, 2084-2102. [CrossRef]

6. Iwanowski, K.; Rushmore, C. Introducing the eco-friendly hotel. Cornell Hosp. Q. 1994, 35, 34-38.

7. Luthra, S.; Kumar, V.; Kumar, S.; Haleem, A. Barriers to implement green supply chain management in automobile industry using interpretive structural modeling technique: An Indian perspective. J. Ind. Eng. Manag. 2011, 4, 231-257. [CrossRef]

8. McCullough, B.P.; Orr, M.; Kellison, T. Sport ecology: Conceptualizing an emerging subdiscipline within sport management. J. Sport Manag. 2020, 34, 509-520. [CrossRef]

9. Lado, A.A.; Boyd, B.G.; Wright, P. A competency-based model of sustainable competitive advantage: Toward a conceptual integration. J. Manag. 1992, 18, 77-91. [CrossRef]

10. Barney, J.B. Firm resources and sustained competitive advantage. J. Manag. 1991, 17, 99-120. [CrossRef]

11. Gerrard, B. What does the resource-based view "bring to the table" in sport management research? Eur. Sport Manag. Q. 2003, 3, 139-144. [CrossRef]

12. Hofer, C.W.; Schendel, D. Strategy Formulation: Analytical Concepts; West Publishing: Saint Paul, MN, USA, 1978.

13. Løwendahl, B.R. Strategic Management of Professional Service Firms; Copenhagen Business School Press: Hendon, VA, USA, 2005.

14. Wright, R.W. The effects of tacitness and tangibility on the diffusion of knowledge-based resources. Acad. Manag. Proceed. 1994, 1994, 52-56. [CrossRef]

15. Mercado, H.U.; Walker, M. The resource-worthiness of environmental responsibility: A resource-based perspective. Corp. Soc. Responsib. Environ. Manag. 2013, 22, 208-221.

16. McCullough, B.P.; Orr, M.; Watanabe, N. Measuring externalities: The imperative next step to sustainability assessment in sport. J. Sport Manag. 2019, 34, 393-402. [CrossRef]

17. Kellison, T.; Hong, S. The adoption and diffusion of pro-environmental stadium design. Eur. Sport Manag. Q. 2015, 15, 249-269. [CrossRef]

18. Mercado, H.U.; Walker, M. The value of environmental social responsibility to facility mangers: Revealing the perceptions and motives for adopting ESR. J. Bus. Ethics 2012, 110, 269-284. [CrossRef]

19. MacIntosh, E.; Apostolis, N.; Walker, M. Environmental responsibility: Internal motives and customer expectations of a winter sport provider. J. Sport Tour. 2013, 18, 99-116. [CrossRef]

20. Casper, J.; Pfahl, M. Environmental sustainability practices in U.S. NCAA Division III athletics departments. Int. J. Event Manag. Res. 2015, 10, 12-36.

21. Casper, J.; Pfahl, M.; McSherry, M. Athletics department awareness and action regarding the environment: A study of NCAA athletics department sustainability practices. J. Sport Manag. 2010, 26, 11-29. [CrossRef] 
22. Kellison, T.; Trendafilova, S.; McCullough, B. Considering the social impact of sustainable stadium design. Int. J. Event Manag. Res. 2015, 10, 63-83.

23. Mallen, C.; Adams, L.; Stevens, J.; Thompson, L. Environmental sustainability in sport facility management: A Delphi study. Eur. Sport Manag. Q. 2010, 10, 367-389. [CrossRef]

24. Pfahl, M. Strategic issues associated with the development of internal sustainability teams in sport and recreation organizations: A framework for action and sustainable environmental performance. Int. J. Sport Manag. Recreat. Tour. 2010, 6, 37-61. [CrossRef]

25. Trendafilova, S.; Kellison, T.; Spearman, L. Environmental sustainability in sport facilities in East Tennessee. J. Facil. Plan. Design Manag. 2014, 2, 1-10.

26. Rubin, H.; Rubin, I. Qualitative Interviewing: The Art of Hearing Data; SAGE Publications: Thousand Oaks, CA, USA, 2011.

27. Yin, R. Case Study Research: Design and Methods; SAGE Publications: Thousand Oaks, CA, USA, 2013.

28. Flyvbjerg, B. Five misunderstandings about case-study research. Qual. Inq. 2006, 12, 219-245. [CrossRef]

29. Green Sport Alliance. Available online: http://greensportsalliance.org (accessed on 24 April 2017).

30. IAVM. Available online: http://www.iavm.org/about-us (accessed on 24 April 2017).

31. Miles, M.; Huberman, M.; Saldaña, J. Qualitative Data Analysis: A Methods Sourcebook; SAGE Publications: Thousand Oaks, CA, USA, 2014.

32. Ross, W.J. Investigating Managerial Priority of Environmental Inputs and Outputs in Public Assembly Venues. Ph.D. Thesis, University of South Carolina, Columbia, SC, USA, 2019.

Publisher's Note: MDPI stays neutral with regard to jurisdictional claims in published maps and institutional affiliations.

(C) 2020 by the authors. Licensee MDPI, Basel, Switzerland. This article is an open access article distributed under the terms and conditions of the Creative Commons Attribution (CC BY) license (http://creativecommons.org/licenses/by/4.0/). 